\title{
Impact of Serum Adiponectin Concentration on Birth Size and Early Postnatal Growth
}

\author{
IKUHIRO INAMI, TOMOO OKADA, HIDETOSHI FUJITA, MASAMI MAKIMOTO, SHIGEHARU HOSONO, \\ MICHIYOSHI MINATO, SHIGERU TAKAHASHI, KENSUKE HARADA, AND TATSUO YAMAMOTO
}

\author{
Department of Pediatrics [I.I., T.O., H.F., M.Ma., S.H., M.Mi., S.T., K.H.], and Department of Obstetrics and Gynecology [T.Y.], Nihon \\ University School of Medicine, 173-8610, Tokyo, Japan
}

\begin{abstract}
In term neonates, the adiponectin concentration is higher than it is in adults. To determine the relationship between adiponectin and early neonatal growth in a cohort study. Fifty-two neonates at term were studied. Serum adiponectin concentrations, body sizes, and skinfold thicknesses were measured at birth and at 1 mo of age. At birth, cord blood adiponectin concentration correlated positively with birth weight $(r=0.484, p=0.0003)$, birth length $(r=0.524, p<0.0001)$, and sum of the four skinfold thickness measurements $(r=0.378, p=0.0057)$. In a stepwise regression, birth length was the only determinant of cord blood adiponectin concentration. However, at 1 mo of age, serum adiponectin concentration correlated with no anthropometric parameter at all. Between birth and $1 \mathrm{mo}$ of age, the individual change in adiponectin concentration correlated negatively with birth weight. Thus, serum adiponectin concentrations in cord blood have a strong relationship to birth length rather than to body fatness, and this relationship is not demonstrated in 1-mo-old infants. These results imply that hormonal, substrate, or other mechanisms that regulate the relationship between body composition and growth in fetal life are different from those governing these relationships in early postnatal life. (Pediatr Res 61: 604-606, 2007)
\end{abstract}

A diponectin is an adipocytokine produced exclusively by adipocytes and has potential antidiabetic, antiatherosclerotic, and anti-inflammatory properties. Therefore, serum adiponectin concentration may be applied usefully as a biomarker of metabolic syndrome (1). Paradoxically, however, adiponectin concentration is inversely correlated with body fatness in adults (2) and in children (3), unlike the other adipocytokines, such as leptin, interleukin (IL)-6, and tumor necrosis factor (TNF) $\alpha$. Overall, the regulation of adiponectin concentrations and its functions are still not sufficiently understood, especially in growing infants.

Adiponectin is also abundantly present in cord blood of term neonates, at concentrations two to three times higher than those reported in adults $(2,4)$. Recent studies suggest that low adiponectin concentration in small neonates may be one of the mechanisms underlying the long-term consequences of an adverse fetal environment (5) and that small size at birth is associated with increased rates of the metabolic syndrome (6). However, adiponectin must have physiologic functions in the

Received September 27, 2006; accepted December 11, 2006.

Correspondence: Tomoo Okada, M.D., Department of Pediatrics, Nihon University School of Medicine, 30-1, Oyaguchi Kamicho, Itabashi-ku 173-8610, Tokyo, Japan; e-mail: tomokada@med.nihon-u.ac.jp

DOI: $10.1203 / p d r .0 b 013 e 3180459 f 8 a$ fetus and in neonates other than that of merely serving as a biomarker for the development of the metabolic syndrome. Little is known about the roles of adiponectin in the fetus. Recent studies in cord blood suggest that adiponectin, which is positively associated with birth weight, may play an important role in regulating fetal growth $(7,8)$. Furthermore, adiponectin concentration in cord blood correlates positively with gestational age, increasing as the amount of adipose tissue also increases during the last trimester (8). This is in marked contrast to findings in adulthood where increased adiposity is associated with decreased circulating adiponectin. Fetal growth is controlled by insulin and insulin-like growth factors (IGFs) $(9,10)$. Adiponectin is a key regulator of insulin sensitivity (1). Mantzoros et al. (11) demonstrated in a crosssectional study that the positive association between adiponectin and birth length is independent of maternal and perinatal factors and that the association may reflect a direct effect of adiponectin or an adiponectin-mediated increase in the sensitivity of tissues to insulin and components of the IGF system. However, in contrast to the role of insulin in fetal growth, the growth hormone system has a dominant role in postnatal period (10).

The aim of the present study was to determine the relationship of adiponectin concentrations and early postnatal growth. We investigated the association between anthropometric parameters and adiponectin concentrations at birth and at $1 \mathrm{mo}$ of age in a cohort study.

\section{SUBJECTS AND METHODS}

Subjects. Informed consent was obtained from all parents, and the study was approved by the University Ethics Committee (Nihon University, Itabashi Hospital).

From September 2004 to March 2005, 63 healthy neonates (37 males, 26 females) who were born by uneventful vaginal delivery or cesarean section in the maternity ward of our university hospital were included consecutively in the study. Infants whose mothers had some complications, and infants with a gestational age of $<37 \mathrm{wk}$ or $<41 \mathrm{wk}$, asphyxia at birth, intrauterine infections, or organic disorders were excluded. Anthropometric parameters and adiponectin concentrations were measured at birth and at 1 mo of age.

Anthropometry. The body weight of each neonate was determined to the nearest $1 \mathrm{~g}$ using an electronic scale. The body length was measured to the nearest $0.1 \mathrm{~cm}$ in the supine position with a length board. Head and chest circumferences were measured with a tape measure to the nearest $0.1 \mathrm{~cm}$. The ponderal index was obtained by the following formula: body weight $(\mathrm{g}) / \mathrm{body}$ length $(\mathrm{cm})^{3}$. Triceps, biceps, suprailiac, and subscapular skinfold thicknesses were measured on the left side of the body using a skinfold caliper (Holtain Ltd., 
Crosswell, Crymych, UK). One investigator (I.I.) performed all the skinfold thickness measurements, using the procedure reported by Schmelzle et al. (12). Adiponectin measurements. The serum adiponectin concentrations were determined by enzyme-linked immunosorbent assay (Otsuka Pharmaceutical Co., Ltd., Tokyo, Japan). A linear curve was obtained with the range of recombinant adiponectin between $0.375 \mathrm{ng} / \mathrm{mL}$ and $12.0 \mathrm{ng} / \mathrm{mL}$ and the dilution curve of human plasma was parallel to the standard curve. Inter- and intra-assay coefficients of variations were $7.4 \%$ and $3.3 \%$, respectively. At birth, cord blood sampling was performed from the umbilical vein after double clamping of the umbilical cord. At $1 \mathrm{mo}$ of age, venous blood was obtained by venipuncture.

Statistical analysis. All statistical analyses were conducted using the statistical package STATVIEW (v. 4.5; Abacus Concepts, Berkeley, CA). Data are given as means \pm standard error (SE). The significance of differences was analyzed by a nonparametric method (Mann-Whitney $U$ test). Simple and multiple regressions were used to assess correlation between variables. A $p$ value $<0.05$ was considered to indicate statistical significance.

\section{RESULTS}

The characteristics of the neonates and their serum adiponectin concentrations are shown in Table 1 . Of the 63 newborns included at birth, 52 had complete measurements both at birth and at $1 \mathrm{mo}$.

Measurements at birth. Anthropometric measurements were shown in table 1 . In cord blood, the serum adiponectin concentration demonstrated no sex difference $(26.2 \pm 1.5$ $\mu \mathrm{g} / \mathrm{mL}$ in male, $22.2 \pm 1.6 \mu \mathrm{g} / \mathrm{mL}$ in female infants, $p=$ 0.0991). Cord blood adiponectin concentration correlated positively with birth weight $(r=0.484, p=0.0003)$, birth length $(r=0.524, p<0.0001)$, chest circumference $(r=0.470, p=$ $0.0004)$, and sum of the four skinfold thicknesses $(r=0.378$, $p=0.0057)$, but did not with head circumference $(r=0.022$, $p=0.2922$ ) (Table 2). These associations remained significant after adjustment for gestational age. In a stepwise regression analysis that included anthropometric measurements as independent determinants, birth length was the only determinant of cord blood adiponectin concentration, explaining $27.5 \%$ of the variability.

Measurements at 1 mo of age. Serum adiponectin concentration at 1 mo of age was significantly higher than that in cord blood $(p<0.0001)$. No significant sex difference $(39.7 \pm 2.2$ $\mu \mathrm{g} / \mathrm{mL}$ in males, $37.9 \pm 2.3 \mu \mathrm{g} / \mathrm{mL}$ in females, $p=0.7458$ ) was found. Serum adiponectin concentration did not correlate with body weight $(r=0.005, p=0.9727)$, body length $(r=$ $0.080, p=0.5708)$, chest circumference $(r=0.108, p=$ $0.4453)$, head circumference $(r=0.006, p=0.9689)$, or sum of skinfold thicknesses $(r=0.077, p=0.5887)$.

Individual difference measurements. The average individual change in adiponectin concentration during first $1 \mathrm{mo}$ of life was $16.1 \pm 1.6 \mu \mathrm{g} / \mathrm{mL}$. Adiponectin concentrations in only four infants declined between birth and 1 mo of age. The

Table 1. Characteristics of the subjects $(\mathrm{n}=52)$

\begin{tabular}{lcc}
\hline & At birth & At $1 \mathrm{mo}$ \\
\hline Body weight, $\mathrm{g}$ & $3054.7 \pm 57.5$ & $4202.8 \pm 68.5$ \\
Body length, cm & $48.3 \pm 0.3$ & $52.9 \pm 0.3$ \\
Ponderal index, $\mathrm{kg} / \mathrm{m}^{3}$ & $27.1 \pm 0.2$ & $28.4 \pm 0.3$ \\
Head circumference, $\mathrm{cm}$ & $33.3 \pm 0.2$ & $36.7 \pm 0.2$ \\
Chest circumference, cm & $31.7 \pm 0,2$ & $35.8 \pm 0.4$ \\
Sum of skinfold thicknesses, $\mathrm{mm}$ & $16.8 \pm 0.3$ & $27.0 \pm 0.5$ \\
Adiponectin concentration, $\mu \mathrm{g} / \mathrm{mL}$ & $23.1 \pm 1.0$ & $38.9 \pm 1.6$ \\
\hline
\end{tabular}

Values are mean $\pm \mathrm{SE}$.
Table 2. Relationship between adiponectin concentration and anthropometric measurements

\begin{tabular}{lcc}
\hline & Correlation coefficients & $p$ \\
\hline At birth & & \\
Body weight & 0.484 & $<0.001$ \\
Body length & 0.524 & $<0.001$ \\
Ponderal index & 0.068 & 0.63 \\
Head circumference & 0.149 & 0.29 \\
Chest circumference & 0.470 & $<0.001$ \\
Sum of skinfold thicknesses & 0.378 & 0.006 \\
At 1 mo & & \\
Body weight & 0.005 & 0.97 \\
Body length & 0.080 & 0.57 \\
Ponderal index & 0.145 & 0.31 \\
Head circumference & 0.006 & 0.97 \\
Chest circumference & 0.108 & 0.45 \\
Sum of skinfold thicknesses & 0.077 & 0.59 \\
\hline
\end{tabular}

individual change in adiponectin concentration correlated negatively with birth weight $(r=-0.296, p=0.0351)$, but did not with birth length $(r=0.233, p=0.1004)$ or sum of the four skinfold thicknesses at birth $(r=0.090, p=0.5280)$.

The mean change in body weight in 1 mo was $1197.3 \pm$ $46.5 \mathrm{~g}, 4.6 \pm 0.2 \mathrm{~cm}$ in body length and $10.1 \pm 0.6 \mathrm{~mm}$ in the sum of skinfold thicknesses (Table 1). The association between these anthropometric changes and the individual changes in adiponectin concentrations was analyzed by simple regression, and no significant correlations were demonstrated among the parameters.

\section{DISCUSSION}

In the present study, we confirm that adiponectin concentrations in cord blood are higher than those reported in adolescents and in adults, in whom values in the range of 2.5 to 38.5 are found (13), and are strongly related to birth weight and birth length by simple regression analysis. However, these relationships were not demonstrated in 1-mo-old infants.

Previously, others have reported the relationship of cord blood adiponectin concentration to birth weight in different ethnic groups $(7,8,14-16)$. All the reports demonstrated that cord blood adiponectin concentration correlates positively with birth weight, in contrast to the findings in adults. However, in the present study, following stepwise analysis, birth length was the only determinant of cord blood adiponectin concentration. Our results are consistent with the report by Mantzoros et al. (11), who suggest that the association with birth length may reflect an effect of adiponectin. This may reflect the fact that fetal growth is controlled by actions of insulin and IGFs, which are regulated by adiponectin acting as an insulin sensitizer $(9,10)$. Furthermore, recent studies on the effects of adiponectin on bone metabolism demonstrate that adiponectin activates osteoblasts $(17,18)$, an effect that may explain the correlation of adiponectin and linear growth. In an in vivo study of adiponectin-overexpressing mice, trabecular bone mass was increased along with a suppression of bone resorption (17). In human neonates, fetal growth is dependent on very active bone formation and resorption of type I collagen, and fetal osteoblasts dominate the proliferation phase of development rather than the maturation phase (19). These findings suggest that 
adiponectin, as well as the insulin-mediated growth system, may have a direct effect on fetal bone growth. In perimenopausal women, conversely, adiponectin concentrations correlate negatively with bone mineral density (20), but it is unclear whether this finding has any relationship to our observations in growth infants because perimenopausal women are well past the period of linear growth. In any case, more studies are necessary to further clarify the effect of adiponectin on fetal bone growth.

Another important finding of the present study is that the association between adiponectin and body size, including height, weight, and skinfold thickness, is not demonstrated at all at 1 mo of age. Moreover, the change in adiponectin concentration during the neonatal period does not correlate with height gain, weight gain, or subcutaneous fat accumulation. As discussed earlier, fetal growth is controlled by insulin and IGFs $(9,10)$. In human cord blood, the insulin level is correlated with birth weight and neonatal length, but not with growth hormone level (21). Conversely, growth hormone has a predominant role in the postnatal period (10), and a study of children with congenital growth hormone deficiency (22) provides evidence that growth hormone has a minimal effect on intrauterine growth but a significant effect during infancy. Our findings, in contrast, suggest that adiponectin has an effect on fetal growth, but no effect on early postnatal growth, at least in the first month of life. Taking these observations together, the hormonal data imply that hormonal regulation of growth may change drastically in the early neonatal period and provide avenues for future research on the interplay of adiponectin, insulin, growth hormone, and IGF-I in the regulation of early postnatal growth.

Finally, we have demonstrated that the individual change in adiponectin concentrations during the first month of life correlated negatively with birth weight. In a cohort study following infants from birth to $2 \mathrm{y}$ of age, a decrease in serum adiponectin concentration was related to increasing age and to greater weight gain in small for gestational age (SGA) infants (23). Cianfarani et al. (24) also demonstrated that adiponectin concentrations are reduced in SGA children with postnatal catch-up growth. The precise mechanisms responsible for these observations remain to be delineated.

In conclusion, our results reveal that adiponectin concentrations in cord blood are strongly related to birth length rather than body fatness and that the relationship is not demonstrated in 1-mo-old infants. Moreover, birth weight itself affects the subsequent postnatal change in adiponectin concentration during the initial $30 \mathrm{~d}$ of life. These results imply that the hormonal regulation of growth and the physiologic effect of adiponectin changes drastically in the early neonatal period. Further, if one considers that birth weight bears a crude relationship with body fat at birth, the results also imply that body fat at the time of birth controls, in some yet unidentified fashion, the progression of adiponectin changes during the first month of life. Whether these changes bear any relationship to a predisposition to develop metabolic syndrome in low birth weight infants remains to be studied.

Acknowledgments. The authors thank the infants and their parents for participating in the study. Drs. Okada, Minato, and
Takahashi designed the study. Dr. Inami and Fujita measured the subjects and corrected anthropometric data. Drs. Inami, Okada, and Harada analyzed the data. Drs. Hosono and Makimoto provided advice and recruitment of subjects. Dr. Inami prepared first draft of the manuscript. All the authors contributed to revision of the manuscript.

\section{REFERENCES}

1. Trujillo ME, Scherer PE 2005 Adiponectin-journey from an adipocyte secretory protein to biomarker of the metabolic syndrome. J Intern Med 257:167-175

2. Arita Y, Kihara S, Ouchi N, Takahashi M, Maeda K, Miyagawa J, Hotta K, Shimomura I, Nakamura T, Miyaoka K, Kuriyama H, Nishida M, Yamashita S, Okubo K, Matsubara K, Muraguchi M, Ohmoto Y, Funahashi T, Matsuzawa Y 1999 Paradoxical decrease of an adipose-specific protein, adiponectin, in obesity. Biochem Biophys Res Commun 257:79-83

3. Okada T, Saito E, Kuromori Y, Miyashita M, Iwata F, Hara M, Harada K 2006 Relationship between serum adiponectin level and lipid composition in each lipoprotein fraction in adolescent children. Atherosclerosis 188:179-183

4. Shimabukuro M, Higa N, Asahi T, Oshiro Y, Takasu N, Tagawa T, Ueda S, Shimomura I, Funahashi T, Matsuzawa Y 2003 Hypoadiponectinemia is closely linked to endothelial dysfunction in man. J Clin Endocrinol Metab 88:3236-3240

5. Kamoda T, Saitoh H, Saito M, Sugiura M, Matsui A 2004 Serum adiponectin concentrations in newborn infants in early postnatal life. Pediatr Res 56:690-693

6. Phillips DI 2004 Fetal programming of the neuroendocrine response to stress: links between low birth weight and the metabolic syndrome. Endocr Res 30:819-826

7. Sivan E, Mazaki-Tovi S, Pariente C, Efraty Y, Schiff E, Hemi R, Kanety H 2003 Adiponectin in human cord blood: relation to fetal birth weight and gender. J Clin Endocrinol Metab 88:5656-5660

8. Kajantie E, Hytinantti T, Hovi P, Andersson S 2004 Cord plasma adiponectin: a 20 -fold rise between 24 weeks gestation and term. J Clin Endocrinol Metab 89:4031-4036

9. Baker J, Liu JP, Robertson EJ, Efstratiadis A 1993 Role of insulin-like growth factors in embryonic and postnatal growth. Cell 75:73-82

10. Gluckman PD, Sizonenko SV, Bassett NS 1999 The transition from fetus to neonate-an endocrine perspective. Acta Paediatr Suppl 88:7-11

11. Mantzoros C, Petridou E, Alexe DM, Skalkidou A, Dessypris N, Papathoma E, Salvanos H, Shetty G, Gavrila A, Kedikoglou S, Chrousos G, Trichopoulos D 2004 Serum adiponectin concentrations in relation to maternal and perinatal characteristics in newborns. Eur J Endocrinol 151:741-746

12. Schmelzle HR, Fusch C 2002 Body fat in neonates and young infants: validation of skinfold thickness versus dual-energy X-ray absorptiometry. Am J Clin Nutr 76:1096-1100

13. Baratta R, Amato S, Degano C, Farina MG, Patene G, Vigneri R, Frittitta L 2004 Adiponectin relationship with lipid metabolism is independent of body fat mass: Evidence from both cros-sectional and intervention studies. J Clin Endocrinol Metab 89:2665-2671

14. Tsai PJ, Yu CH, Hsu SP, Lee YH, Chiou CH, Hsu YW, Ho SC, Chu CH 2004 Cord plasma concentrations of adiponectin and leptin in healthy term neonates: positive correlation with birthweight and neonatal adiposity. Clin Endocrinol (Oxf) 61:88-93

15. Kotani Y, Yokota I, Kitamura S, Matsuda J, Naito E, Kuroda Y 2004 Plasma adiponectin levels in newborns are higher than those in adults and positively correlated with birth weight. Clin Endocrinol (Oxf) 61:418-423

16. Pardo IM, Geloneze B, Tambascia MA, Barros-Filho AA 2004 Hyperadiponectinemia in newborns: relationship with leptin levels and birth weight. Obes Res $12: 521-524$

17. Oshima K, Nampei A, Matsuda M, Iwaki M, Fukuhara A, Hashimoto J, Yoshikawa H, Shimomura I 2005 Adiponectin increases bone mass by suppressing osteoclast and activating osteoblast. Biochem Biophys Res Commun 331:520-526

18. Luo XH, Guo LJ, Yuan LQ, Xie H, Zhou HD, Wu XP, Liao EY 2005 Adiponectin stimulates human osteoblasts proliferation and differentiation via the MAPK signaling pathway. Exp Cell Res 309:99-109

19. Nakano K, Iwamatsu T, Wang CM, Tarasima M, Nakayama T, Sasaki K, Tachikawa E, Noda N, Mizoguchi E, Osawa M 2006 High bone turnover of type I collagen depends on fetal growth. Bone 38:249-256

20. Jurimae J, Rembel K, Jurimae T, Rehand M 2005 Adiponectin is associated with bone mineral density in perimenopausal women. Horm Metab Res 37:297-302

21. Osmanagaoglu MA, Osmanagaoglu S, Bozkaya H 2005 The association of birthweight with maternal and cord serum and amniotic fluid growth hormone and insulin levels, and with neonatal and maternal factors in pregnant women who delivered at term. J Perinat Med 33:149-155

22. Mehta A, Hindmarsh PC, Stanhope RG, Turton JP, Cole TJ, Preece MA, Dattani MT 2005 The role of growth hormone in determining birth size and early postnatal growth, using congenital growth hormone deficiency (GHD) as a model. Clin Endocrinol (Oxf) 63:223-231

23. Iniguez G, Soto N, Avila A, Salazar T, Ong K, Dunger D, Mericq V 2004 Adiponectin levels in the first two years of life in a prospective cohort: relations with weight gain, leptin levels and insulin sensitivity. J Clin Endocrinol Metab 89:5500 5503

24. Cianfarani S, Martinez C, Maiorana A, Scire G, Spadoni GL, Boemi S 2004 Adiponectin levels are reduced in children born small for gestational age and are inversely related to postnatal catch-up growth. J Clin Endocrinol Metab 89:13461351 